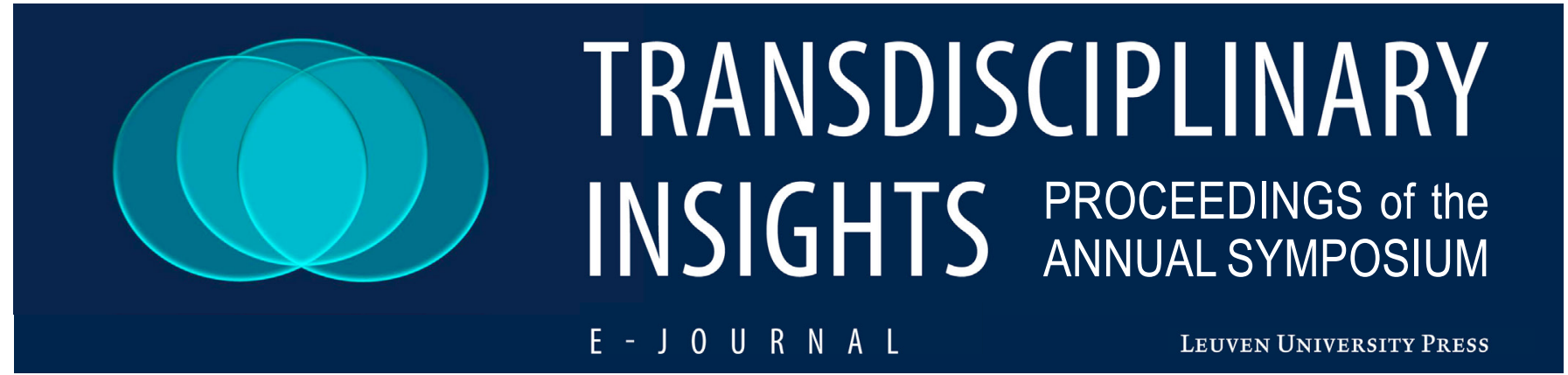

2021 KU Leuven Facing the Future: "How to increase societal impact?" https://rega.kuleuven.be/cev/Symposium/facing-the-future/Program-2021 Leuven, 5 May 2021
Program

17h15 - 17h20 Introduction by the Institute for the Future

17h20 - 17h45 STEAM+: Transforming higher education through collaborative play

17h45 - 18h10 InclusiVaart. (Re)defining shared neighborhood spaces

18h10 - 18h35 Conceptualising Open Science in the 21st Century

18h35 - 19h00 Coronavirus Pandemic Preparedness

\title{
STE(A)M+: Transforming Higher Education through Collaborative Play
}

\begin{abstract}
Ilse Vranken, ${ }^{1,2^{*}}$ Dominique Troost, ${ }^{1,3^{*}}$ Raad Sharar, ${ }^{1,4^{*}}$ Pieter Hanssens, ${ }^{1,5^{*}}$ Simon Van Espen, ${ }^{1,6^{*}}$ Ronald Cruz Salamat, ${ }^{1,7^{*}}$ Iryna Nykytiuk, ${ }^{1,8^{*}}$ Hannes De Praitere, ${ }^{1,9^{*}}$ Inge
\end{abstract} Smeers, ${ }^{1,10}$ ToTran Nguyen, ${ }^{1,11}$ Anne Snick ${ }^{1,12 \$}$

${ }^{1} \mathrm{KU}$ Leuven, Honours Programme Transdisciplinary Insights, Institute for the Future, Belgium;

${ }^{2} \mathrm{KU}$ Leuven, School for Mass Communication Research, Faculty of Social Sciences, Belgium;

${ }^{3} \mathrm{KU}$ Leuven, Master's student in Psychology, Faculty of Psychology and Educational Sciences, Belgium;

${ }^{4} \mathrm{KU}$ Leuven, Master's student in Social and Cultural Anthropology, Faculty of Social Sciences, Belgium;

${ }^{5} \mathrm{KU}$ Leuven, Bachelor's student in Industrial Sciences, Faculty of Engineering and Technology, Belgium;

${ }^{6} \mathrm{KU}$ Leuven, Bachelor's student in Economics, Faculty of Economics and Business, Belgium;

${ }^{7} \mathrm{KU}$ Leuven, Master's student in Sustainable Development, Faculty of Sciences, Belgium;

${ }^{8} \mathrm{KU}$ Leuven, Master's student in Business Administration, Faculty of Economics and Business, Belgium;
${ }^{9} \mathrm{KU}$ Leuven, Bachelor's student in Geography, Faculty of Sciences, Belgium;

${ }^{10} \mathrm{KU}$ Leuven, Laboratory of Reproductive Genomics, Department of Human Genetics, Belgium;

${ }^{11} \mathrm{KU}$ Leuven, Department of Work and Organisation Studies, Faculty of Economics and Business, Belgium; ${ }^{12} \mathrm{Club}$ of Rome - EU, Belgium;

*Authors contributed equally;

\$Corresponding author: anne.snick@scarlet.be.

\section{Abstract}

Our world is facing various wicked problems, such as climate change and extinction. These complex problems require an in-depth understanding. STEM disciplines in higher education play a crucial role in preparing students to solve such problems in their career. Yet it can be questioned whether STEM in higher education offers all the elements required to prepare students for a sustainable future. Additionally, a sole focus on STEM fields may not contribute to finding solutions to these problems. With STE(A)M in higher education, 
we explore what the missing element in higher education is and how higher education can be improved. We addressed this question within the Honours Programme Transdisciplinary Insights of the Institute for the Future at KU Leuven. Within this programme, a team of students, PhD researchers and coaches from various disciplines examined the educational system and explored how students can be better prepared to co-create a more sustainable future. This learning path was supported by reading books about systems thinking, watching documentaries, following co-creative workshops, and engaging in team discussions. In this process, we found that the following four key elements could be given a greater emphasis in education: transdisciplinarity, systems thinking, co-creation, and critical thinking. To promote this, we created a board game that aims to make learning about the importance of these elements engaging. While playing this game, we learned that we can bring students from different disciplines together and foster critical thinking and reflections. These insights illustrate how creative tools (e.g. board games) can be used in higher education to foster important skills that can prepare students for a sustainable future. Since this game, developed by students for students, is entirely learner-driven, it departs from the current educational system in which knowledge is mainly transferred by professors. An important advantage of such initiatives is that they foster co-creation and learning between students. Our findings have been summarised in a small video. ${ }^{1}$

\section{Key words}

sustainable higher education, games, transdisciplinarity, systems thinking, critical thinking

\section{Title of the original challenge}

STE(A)M in Higher Education (https://rega.kuleuven.be/tdi/tdi-challenges/steamin-higher-education) 